\title{
On the Features of Female Language in English
}

\author{
Qi Pan \\ English Department, Zhenjiang Watercraft College of PLA, Zhenjiang, China \\ Email: panqi_tracy@126.com
}

\begin{abstract}
Language is a means of verbal communication. People use language to communicate with each other. In the society, no two speakers are exactly alike in the way of speaking. As a form of social behavior, language like other social behaviors, entertains gender difference as well. This paper tries to describe the major features of female language from these perspectives: phonology, vocabulary, grammar, conversational topics and styles. The factors that shape the features of female language are not only because of the influence of physiology and psychology, but also because of the influence of the society and the culture. From the discussion of the features of female language, more attention should be paid to language use in social context.
\end{abstract}

Index Terms - female language, gender difference, features, factors

\section{INTRODUCTION}

People of different social groups have their own unique language, the language they use is called social dialects. Social dialect refers to a variety of language that is commonly found among a certain group of people who have some social, cultural or economic features in common, and that may inform on the speaker's social positions accordingly. Male and female language is different. Women, as a social group, have their own language characteristics. In the early 1970s, female language was paid more attention by the linguists, psychologists and sociologists. And "female language" was also used to describe the differences due to gender differences in the phenomenon of language.

Language and gender studies is a subfield of sociolinguistics, which deals with linguistic gender differentiation reflected in pronunciation, vocabulary and grammar, as well as women's and men's speech interaction patterns. Additionally, sexism in language is also a topic widely studied.

\section{MAJOR FeATURES OF FEMALE LANGUAGE}

Female language, whether spoken or written language has its own unique characteristics. The following tries to describe the major features of female language from these perspectives: phonology, vocabulary, grammar, conversational topics and styles.

\section{A. In Phonology}

Famous phonetician O'Conner (1973) has pointed out that pronunciation was once a marker of social status and Kuwabara (1984) also stated that verbal signal is a complex acoustics activity and it conveys not only the content of language, but also the information regarding the speaker's identity, personality and feelings.

In Phonology, features of women's language are mainly present in pronunciation, pitch and tone.

a. Pronunciation

Pronunciation provides the best evidence of gender-based language forms. In general, women's pronunciation tends to be more "correct", more standard than men's. This idea can be illustrated with the following examples.

Example 1.The suffix-ing has different pronunciations in male and female usage. In Norwich (east England), women pronounce-ing, phonetically transcribed as $[\eta]$ while men pronounce [n]. Women pronounce the word working as ['w3:king] while men pronounce this word as ['w3:kin].

Example 2.Men and women's pronunciations are different when they pronounce the initial [h].As for the word home, women pronounce [hзum] while men pronounce ['3um]. In a word, many studies have shown that women's pronunciation generally approximates more closely to those of the standard language than do men's pronunciation of the same social background, age and so on.

b. Pitch

Numerous documents have shown that high pitch is one of the distinguished features of women's language and women usually speak in higher pitch than men. Robin Lakoff asserted that women use "a peculiar sentence intonation pattern---which changes a declarative answer into a question".

Sometimes women are inclined to use the rising pitch to answer the general questions. For example, when the husband asks his wife, perhaps the wife answers: When do you want to go to the store? /Oh...about four-thirty?

Obviously the intonation, which the wife uses, contains hesitance and inquiry.

c. Tone

Women's changeable tone can express their rich emotions and sounds more gentle and affectionate. Especially in British and American society, women usually use reverse accent, which greatly shows the gentleness of women's tone. 
They often use rising tone when answering men's questions. This speech style will make people feel at ease and comfortable. For example:

Husband: When will dinner be ready?

Wife: of....around six o'clock $\uparrow$ ?

In this example, obviously wife is cooking and she knows when the dinner can be ready, but she answers her husband with rising tone, thus this tone has shown the wife's gentleness.

\section{B. In Vocabulary}

In vocabulary, the features of women's language are mainly seen in using intensifiers, extravagant adjectives, swear words, expletives, euphemism, and polite expressions.

a. Intensifiers

Women are likely to use such intensifiers as so, much, quite, vastly and etc. (Key, 1972)

Numerous documents show that women, compared with men, use more intensifiers to strengthen what they want to express. Some adverbs, like awfully, pretty, terribly, vastly, nice, quite and so, are more easily found in women's language.

b. Adverbs and Adjectives

Jespersen said that there are greater differences in the way the sexes use the adverb than the way they use the adjectives. He suggested that "the fondness of women for hyperbole will very often lead the fashion with regard to adverbs of intensity, and these are very often used with disregard of their proper meaning"(Jesperson, 1922, p.250)

And he also found that women like to use such kind of expressions:

$\mathrm{He}$ is so charming! It is so lovely! Thank you so much! Do you know that you look such a duck this afternoon? (Jesperson, 1922)

Like using more intensifiers, women like to use more hyperbole adjectives. For example, a lady expressed her thanks to the hostess for one dinner like this:

"It's a gorgeous meal. Thank you."

Researches show us that adjectives, like adorable, cute, divine, dreamy, gorgeous, heavenly, cool, great, lovely, terrific, wonderful and so on, are more frequently heard from women's mouths.

c. Expletives

When male and female use expletive, female is more careful and they avoid using crude words. These expressions such as my dear, my goodness, Goodness often appear in women's language. On the contrary, these words and sentences such as "God damn it","damned and shit" are often found in the men's language. These crude words and sentences are taboos. When men use the word "shit", women often use "Oh, dear" to express their intensive feelings.

d. Euphemism and Polite Expressions

Additionally, women use euphemism and polite expressions more frequently. Euphemism, in fact, is one way to use one implicit, vague expression to substitute for unpleasant expressions.

According to Jespersen, women are euphemistic, exercising "a great and universal influence on linguistic development through their instinctive shrinking from coarse and gross expression and their preference for refined and veiled and indirect expressions". (Jespersen, 1922, p.246)Women use euphemistic substitutes. For example, women say "the other place" instead of "hell", say "My period now", "My friend came," "My grandmother has come to stay", "My auntie has come to stay", or "I fell off the roof", to express "menstruation". They use "the small of one's back" instead of "buttocks", "stout" instead of "fat", and "vestal virgin" instead of "spinster".

Similarly, in interactions, euphemisms are also preferred by women. For instance:

Babara: What do you think of the color of my coat?

Nancy: It's interesting.

In this simple dialogue, Nancy's answer "It's interesting", in reality, is designed to express the unpleasant implication: I don't like the color of the coat.

Women are more likely to speak politely. They often use expressions with polite implications, like "thank you", "please", "you are so kind", "would you please...", "Would you mind...", "Would you kindly...” and the like.

\section{In Grammar}

Although, so far, there is no enough evidence to prove that some grammar structures are solely used by women, yet through the analysis of the linguistic materials collected by linguists, women are indeed found to use the following grammar structures more.

a. Tag Questions

In ayntax as well as usage, a tag question is midway between a statement and an outright question:

The way prices are rising is horrendous, isn't it?

Lakoff proposed that tags are used when a speaker is atating a claim but has less than full confidence in the truth of the claim. In some situations, then, a tag question would be perfectly legitimate sentence form.

She proposed that women used one particular type of tag question more than men. The type in which the speaker's own opinions are being expressed, as in the example above. The effect is to convey uncertainty and lack of conviction.

b. Hedges 
Hedges are words that convey the sense that the speaker is uncertain about what he or she is saying, or can not vouch for the accuracy of the statement, such as "kind of", "sort of", "you know", "I think", "I suppose", and "I guess" and etc.

Hedges seem to appear more often in women's speech. There is another justifiable use in which the hedge mitigates the possible unfriendliness or unkindness of a statement, that is, for the sake of politeness. Besides, in contrast with men, women usually apply embedded imperatives to ask someone to do something. "Will you please open the window?", "Please close the door", "On your way back, could you please bring that here?" and so on are usually used by women.

c. Hypercorrect Grammar

This involves an avoidance of terms considered vulgar of coarse, such as "ain't" and use of precise pronunciation, such as sounding the final $\mathrm{g}$ in words such as "going" instead of the more casual "goin". This characteristic is related to "superpolite" language.

\section{In Conversational Topics and Styles}

In the early 1970s, famous sociolinguist Hymes has once stated that in any speech community, the speech act is very likely to be the gender marker of the community members. Thus, women's speech act will speak for women's gender identity and their linguistic features in conversations will help us know more about women's social realities and gender identity.

a. Subjects

Males and females seem to be different even in the things they talk about. Usually men are not familiar with the words, which are related to cloth, color, sewing and the style of women's dresses. Women are not familiar with the words which are related to the reparation of cars, the equipment of pipes and sports. Topics that are considered trivial or unimportant are women's domain. There are also many tabooed subjects for women. Tabooed subjects can vary widely: sex; death; excretion; bodily functions; religious matters, and politics.

b. Discourse

For women, conversations are negotiations for closeness in which people try to seek and give confirmation and support, and to reach consensus. They try to protect themselves from others' attempts to push them away. Life, then, is a community, a struggle to preserve intimacy and avoid isolation. Though there are hierarchies in this world too, they are hierarchies more of friendship than of power and accomplishment. The difference involves the preferred relations between speaker and addressee. Men are said to prefer this pattern, where a single speaker has the rest of the group as audience, while women tend to break a larger group into a number of smaller conversation groups.

\section{Possible Factors that Shape the Features of Female LanguagE}

The factors that shape the features of female language are not only the influence of physiology and psychology, but also because of the influence of the society and the culture. The difference of social work distribution, cultural factors and social psychological factors are all responsible for the appearance of these characteristics.

\section{A. Social Factors}

As language is closely related to social attitudes and it reflects language's, creators' and users' thought as well as attitudes and cultural values. And people's attitudes are affected by social ideology and their own value orientation, which will, in turn, have great influence on people's evaluations about objects. Therefore, early linguists' attitudes towards women's language are inevitably influenced by their social ideology and value orientation. Specifically speaking, their evaluation about women's language is based on several social factors: women's social status, women's sex role socialization and dominant gender system.

a. Women's Social Status

Industrialized capitalism has sharpened a division between the labor of women and men, and a separation in the location of their activities. Men are more visible in, and ideologically defined by, the public sphere while women are relegated to the domestic sphere. Women have always been and are increasingly among the wage laborers, but even employed women are primarily defined by their family roles.

Women's supposed speech style is often ridiculed and is not considered an acceptable style for either men or women in public affairs. As is mentioned in his 1922 chapter "the Woman", O.Jesperson presents women's language as an aberration of men's language. Women's vocabulary is, he claims, less extensive, their sentences are not as complex as men's, they talk more rapidly and with less thought than do men.

b. Sex Role Socialization

Concerning the sex roles socialization theory, Pamela Fishmen has ever described like this:

"Discussions of the way women act often rely on some notion of a female 'personality'. Usually, socialization is used to explain this personality. Women are seen as more insecure, dependent and emotional than men because of the way that they are raised."(Fishmen, 1980, p.127) In analyzing men's and women's speech style with this socialization theory, Lakoff (1990)clearly pointed out: "Language patterns into which women are most frequently seen as having been socialized include hesitance, insecurity,indirectness, weakness, deviousness, politeness, and hypercorrection, which is itself sometimes appealed to an indication of a feeling of inferiority with one's own way of speaking... Men, on the other 
hand, are perceived as having been socialized into strong, dominant, forceful, and direct ways of talking." Based on the above statements, socialization process has stereotyped women's personality and their language use.

\section{B. Culture Factors}

The relationship between language and culture is interactive and language is one expression, one mirror and carrier of culture. Thus, the image of women's language, of course, is closely linked to cultures, like sex discrimination, western women's subculture and Bible, so is the early evaluations about western women's language. On the whole, in the sense of culture, their evaluations are affected by such factors, like gender culture, gender ideology and gender stereotypes.

a. In Gender Culture

Gender functions in social relations and material conditions through gender systems. In the United States, there are two quite different gender systems operating. One of them is the more publicly known: the dominant system of cultural practices found throughout middle-class European society. That is, in this gender system, males have dominance over women and they are breadwinner status, political participants and so on.

Women's culture, as one subculture of gender culture, has been formed within the division of labor. That is to say, due to the division of labor, women are only subordinated to men. Anthropologists argued that in all cultures women are seen as closer to nature than men by virtue of their involvement in the biological reproduction of the species, while men are seen as closer to culture. Culture, In turn, is more highly valued by humans in their efforts to distinguish themselves from the rest of the animal world. This also provides a basis for the assertion of male superiority over women. This cultural tradition can date back to "Bible". "Bible" claims that man creates the world, while woman is just one rib taken from man. "Bible", to a large extent, advocates patriarchy and emphasizes women's subordinated social status. For example:

Wives, be subject to your husbands as you are to the lord.

Indeed, man was not made from woman, but woman from man. Neither was man created for the sake of woman, but woman for the sake of man.

b. In Gender Ideology

Ideology is the system of beliefs by which people explain, account for, and justify their behavior and interpret and assess that of others. Gender ideology is the set of beliefs that govern people's participation in the gender order, and by which they explain and justify that participation.

Lakoff's (1973) claimed that the ways in which particular semantic and morphological processes are carried conveyed negative attitudes toward women. In particular semantic field, it is easy to find that some words have negative meaning against women, like spinster, bitch, widow, etc. Thus, gender ideologies and gendered speaking patterns were closely related and to some extent, the latter has helped a lot in shaping gender ideology.

\section{CONCLUSION}

Gender differences are a fundamental fact of human life and it is not surprising to find them reflected in language. It should be noted that the distinction between men and women's language is a symptom of a problem in our culture, not the problem itself. Basically it reflects the fact that men and women are expected to have different interests and different roles, hold different types of conversations, and react differently to other people. From the discussion of the features of female language, more attention should be paid to language use in social context. What's more, the linguistic phenomena in speaking community can be understood more thoroughly. Thus, this paper "On the Characteristics of Female Language in English" not only describes and explains these features but also discloses language and social relationships.

\section{REFERENCES}

[1] Cheris, Kramarae. (1981). Women and Men Speaking. Massachusetts: Newbury House Publishers.

[2] Deborah, Tannen. (1993). Gender and Conversational Interaction. New York: Oxford University Press.

[3] Fishman, P. (1980). Conversational Insecurity Language: Social Psychological Perspectives. Oxford: Pergamon Press.

[4] Hudson, R.A. (1996). Sociolinguistics. Cambridge: Cambridge University Press.

[5] Jespersen, Otto. (1922). Language: Its Nature, Development and Origin. London: Allen and Unwin.

[6] Key, Mary. R. (1972). Linguistic Behavior of Male and Female. Linguistics, 6, 15-31.

[7] Kuwabara. (1984). Experiments on Voice Qualities of Vowels in Males and Females and Correlation with Acoustic Features. Language and Speech, 16, 135.

[8] Lakoff. (1975). Language and Woman's Place. New York: Harpers\&Row Publishers.

[9] O'Conner, J.D. (1973). Phonetics. New York: Penguin Books.

Qi Pan was born in Zhenjiang, China in 1987. She received her B.A. degree in English language and literature from Jiangsu University of Science and Technology, China in 2009.

She is currently a tutor in English Department, Zhenjiang Watercraft College of PLA, Zhenjiang, China. Her research interests include Second Language Acquisition Contrastive Studies of English and Chinese. 